\title{
Perioperative Complications in the Cancer Patient: A Robust Prognostic Factor
}

\author{
Frederick Greene \\ Levine Cancer Institute, Charlotte, NC
}

Life is short, art is long, opportunity fleeting, experience deceiving, and judgment difficult.

Hippocrates

As surgeons, we grew up learning about postoperative complications in the forum known as the Morbidity and Mortality (M\&M) conference. We learned that certain genre of complications, such as intra-abdominal infections, myocardial ischemia, pneumonia, and deep venous thrombosis, portend especially detrimental outcomes for our surgical patients. The concept of the M\&M conference developed from the seminal work of Dr. Ernest Amory Codman who, in the early 1900s working at Massachusetts General Hospital, recognized that in order to learn from our mistakes and improve patient care we had to discuss unsuccessful outcomes, quantify and catalogue these misadventures, and follow the course of our patients. ${ }^{1}$ These tenets espoused by Codman were not embraced by his fellow Boston physicians and he was invited to remove himself from the environment of the medical staff and hospital! Codman's early endeavors into developing databases and reporting outcomes served, however, as the basis for the quality initiatives first developed by the American College of Surgeons (ACS) during the infancy of that organization in the second decade of the twentieth century. Subsequently, the creation of risk-adjusted instruments, such as the Veterans Administration (VA)initiated National Surgical Quality Improvement Program

This is an editorial to the article available at doi: $10.1245 / \mathrm{s} 10434-$ 013-3267-0.

\section{(C) Society of Surgical Oncology 2013}

First Received: 20 August 2013;

Published Online: 18 September 2013

F. Greene

e-mail: fgreene@med.unc.edu
(NSQIP) launched in the early 1990s and the ACS-NSQIP promulgated to all hospitals more recently, has provided analytic tools not only to evaluate the consequences of surgical complications during the immediate postoperative period but to assess the ultimate effects of these events on the entire course of an illnesses, such as cancer. As an important derivative from the ACS-NSQIP, the Surgical Risk Calculator recently has been launched to facilitate the computation of the likelihood of 30-day outcomes for a large number of surgical procedures given the presence of preoperative comorbidities. ${ }^{2}$ The late Shukri Khuri, working with his VA colleagues using the VA-NSQIP database, showed that the 30-day complication rate is a robust factor in determining both short- (30-day) and long-term survivals for all patients undergoing eight common operations. ${ }^{3}$ Although not directed previously to cancer patients, Khuri's work suggested that the "inflammatory response" resulting from postoperative complications was a detrimental factor in determining long-term survival and was independent of patients' preoperative risks. The importance of this work had obvious implications for patients with malignancy.

The prognosis of cancer is dependent on adequate staging of patients. More recently, molecular markers along with anatomical staging have been added to the taxonomy of outcomes of cancer patients. ${ }^{4}$ Unfortunately, the role of comorbidities, although championed by some, continues to be unrecognized as a major factor in the outcomes of cancer patients..$^{5}$ Along with this, we have generally failed to understand the importance of the postoperative complication on the future of our cancer patient. Perhaps complicated outcomes are associated with other factors. The adverse effect of blood transfusion has been delineated as a reason for reduced survival in cancer patients, perhaps as a consequence of reduced immunocompetence resulting from transfusion. ${ }^{6}$ Obviously patients with postoperative complications may have an increased 
requirement for blood replacement. Similarly, the increased volume of cases performed by surgeons and treated in hospitals has been highlighted as a potential positive prognostic factor for long-term cancer survival. ${ }^{7}$ The obvious corollary might be that fewer postoperative complications ensue in institutions performing a greater number of operations and having a greater experience with certain cancers.

Previous reports have indicated that when TNM stage has been held constant, patients with postoperative complications undergoing colorectal procedures as well as esophageal and hepatic resection for malignancy have had reduced survival compared with uncomplicated patients. $^{8-10}$ In this issue, Scaife and colleagues from the Huntsman Cancer Center at the University of Utah have added to this body of information, not only by highlighting the research potential gained by melding databases to gain important outcome information, but also by providing additional evidence linking infectious complications with reduced long-term outcomes in cancer patients. ${ }^{11}$ They have used their own registry data as well as data from ACS-NSQIP to capture complication data and to assess the effect of complications on cancer outcomes. Recently, the ACS has begun a pilot program modeled after NSQIP, but targeted especially to the cancer patient. The Cancer Quality Improvement Program, or CQIP (personal communication) as it is known, may be the important "missing link" when it comes to finally obtaining and assessing the detrimental effects of post-operative complications on outcomes in cancer patients. An important, but exceedingly challenging goal is to capture information relating to complications and to abstract these data into existing registries, such as the National Cancer Data Base. This will allow for complications in postoperative patients with cancer to be tracked over time and studied as meaningful host prognostic factors. We must realize, however, that limiting discussion and collection of complications to the traditional and arbitrary "30-day" period is no longer acceptable. Because of improvements in operative management and perioperative care, perhaps as a by-product of utilizing rigorous guidelines, morbidities relating to oncologic procedures frequently occur later than 30 days and must be collected and analyzed to assess the role of these factors in the long-term survival and recurrence of cancer in our patients. ${ }^{12}$
The important message highlighted by the work of Scaife et al. is that we must first understand the consequences of a complicated postoperative course and be ready to discuss these issues and document the findings at M\& $M$ conferences, tumor conferences, and all venues where meaningful data can be collected and entered into existing and future databases that will track patients with malignancy. Only then will we meet the challenge that Dr. Codman articulated 100 years ago.

\section{REFERENCES}

1. Brand RA. Ernest Amory Codman, MD, 1869-1940. Clin Orthop Relat Res. 2009;467:2763-5.

2. Bilimoria KY, Liu Y, Paruch JL, et al. Development and evaluation of the Universal ACS NSQIP surgical risk calculator: a decision aide and informed consent tool for patients and surgeons. J Am Coll Surg. 2013 doi:10.1016/j.jamcollsurg.2013.07. 385.

3. Khuri SF, Henderson WG, DePalma RG, et al., Determinants of long-term survival after major surgery and the adverse effect of postoperative complications. Ann Surg. 2005;242:326-41.

4. Edge SB, Byrd DR, Compton CC, et al. AJCC cancer staging manual, 7th edn. New York: Springer-Verlag, 2009.

5. Piccirrillo JF, Tierney RM, Costas I, et al. Prognostic importance of comorbidity in a hospital-based cancer registry. JAMA. 2004; 291:2441-7.

6. Kooby DA, Stockman J, Ben-Porat L, et al. Influence of transfusions on perioperative and long-term outcome in patients following hepatic resection for colorectal metastases. Ann Surg. 2003;237:860-70.

7. Bach PB, Cramer LD, Schrag D, et al. The influence of hospital volume on survival after resection for lung cancer. $N$ Engl J Med. 2001;345:181-8.

8. Law WL, Choi HK, Lee YM, et al. The impact of postoperative complications on long-term outcomes following curative resection for colorectal cancer. Ann Surg Oncol. 2007;14:2559-66.

9. Hirai T, Yamashita Y, Mukaida H, et al. Poor prognosis in esophageal cancer patients with postoperative complications. Surg Today. 1998;28:576-9.

10. Ito $\mathrm{H}$, Are $\mathrm{C}$, Gonen $\mathrm{M}$, et al. Effect of postoperative morbidity on long-term survival after hepatic resection for metastatic colorectal cancer. Ann Surg. 2008;247:994-1002.

11. Scaife CL, Hartz A, Pappas L, et al. Association between postoperative complications and clinical cancer outcomes. Ann Surg Oncol.

12. Katlic MR, Facktor MA, McKinley KE, et al. ProvenCare lung cancer: a multi-institutional improvement collaborative. $C A$ Cancer J Clin. 2011;61:382-96. 